\title{
Experimental investigation on the coal combustion in a pressurized fluidized bed
}

\author{
Lei Pang ${ }^{1}$, Yingjuan Shao ${ }^{1, *}$, Wenqi Zhong ${ }^{1}, \mathrm{Hao} \mathrm{Liu}^{2, * *}$
}

1. Key Laboratory of Energy Thermal Conversion and Control of Ministry of

Education, School of Energy and Environment, Southeast University, Nanjing 210096, P.R. China

2. Department of Architecture and Built Environment, Faculty of Engineering, University of Nottingham, University Park, Nottingham NG7 2RD, UK

\footnotetext{
${ }^{*}$ Corresponding author

** Corresponding author

E-mail address: yjshao@seu.edu.cn (Y. Shao), Liu.Hao@nottingham.ac.uk (H. Liu)
} 


\section{Abstract}

Pressurized oxy-coal combustion is considered as one of the most promising carbon capture technologies in terms of high carbon capture efficiency and low cost. However, practical operational experience with pressurized coal combustion in a fluidized bed, especially with continuous coal feeding, is still very limited. In this study, a pressurized fluidized bed combustion system was developed and a series of coal combustion experiments were carried out with continuous coal feeding under the pressures from 0.1 to $0.4 \mathrm{MPa}$. The effects of the combustion pressure and stoichiometric air coefficient on the fluidized bed combustion performances of a Chinese lignite in terms of the temperature distribution profile, apparent solid holdup, combustion efficiency, conversion ratio of carbon in coal to $\mathrm{CO}_{2}$ and ash composition were investigated. The experimental results show that an increase in pressure is beneficial to the improvement of combustion efficiency, and the positive effect of increasing stoichiometric air coefficient on the conversion ratio of carbon in coal to $\mathrm{CO}_{2}$ is more obvious with a lower combustion pressure. The bottom ash and fly ash have similar chemical compositions under different pressures. Based on the experimental data, a correlation as the functions of pressure and stoichiometric air coefficient is proposed to predict the conversion ratio of carbon in coal to $\mathrm{CO}_{2}$.

Keywords: Pressurized coal combustion; Fluidized-bed; stoichiometric air coefficient. 


\section{Introduction}

Oxy-fuel combustion has been considered as one of the most promising carbon capture technologies to reduce $\mathrm{CO}_{2}$ emissions from industrial combustion processes [14]. For the conventional oxy-fuel technology, the boiler operates at atmospheric pressure, while the air separation unit (ASU) and compression purification unit (CPU) run under pressure [5]. The pressure mismatch among the ASU, boiler and CPU results in the reduction of net efficiency [6]. In order to reduce the energy penalties and improve the efficiency, the pressurized oxy-fuel combustion technology was proposed as the solution, and many researchers have conducted technical and economic studies on the pressurized oxy-fuel combustion system [7-11]. Hong et al. [7] analyzed a pressurized oxy-fuel combustion power cycle and indicated that the pressurized cycle had better performance than the atmospheric one in terms of the thermal energy recovery and gross power output. Their results showed that the net efficiency increased by nearly $3 \%$ if the combustor was operated at 10 bar instead of at 1.238 bar. Zebian et al. [8] performed the simultaneous multi-variable gradient-based optimization on a 300 MWe pressurized oxy-coal combustion process. The optimum operating pressure was found to be within a range of 3.75-6.25 bar. Many other researchers have also obtained positive simulation results under pressurized oxy-combustion conditions [9-11].

The pressurized combustion technology is the prerequisite for the realization of pressurized oxy-fuel combustion. Over the past several decades, the effect of pressure on coal thermal conversions has attracted widespread attention as an integral part of the 
development of clean coal technologies, in particular, the integrated gasification combined cycle (IGCC) process. Many researchers have focused on the influence of pressure on the reaction rates including the coal combustion rate, devolatilization rate and char combustion rate. Saastamoinen et al. [12] developed an electrically heated pressurized entrained flow reactor to investigate the effect of pressure on the pulverized coal combustion. Their experimental study showed that increasing pressure strongly enhanced the combustion rate of less reactive coals. Besides, the effect of pressure increase on the combustion rate was the greatest at near $0.1 \mathrm{MPa}$ and smaller at higher pressures. Lu [13] investigated the characteristics of 10 different fuels' devolatilization and char oxidation under pressurized fluidized bed combustion conditions using a laboratory-scale batch reactor. The results showed the pressure had a stronger effect on devolatilization but a weaker effect on char burnout. However, Macneil and Basu [14] reported that the specific burning rate of char increased with pressure up to $0.5 \mathrm{MPa}$ but further increase in pressure led to a decrease in the rate. This phenomenon was also observed by other researchers [15-17]. Lin et al. [18] measured the char combustion rate in a fixed bed and found it increasing with pressure in both the chemical-kinetic and internal-diffusion control zones while it was invariant with pressure in the externaldiffusion control zone. This may explain why the pressure was observed to have played different roles in the previous studies [13-14]. In addition to the reaction rate, researchers have also investigated the influence of pressure on heat transfer, pollutant emission and ash formation [19-23]. 
The advantages of fluidized bed combustion (FBC) are well-known in terms of its ability to burn a wide range of fuels, efficient sulfur removal and low NOx emissions. Pressurized fluidized bed combustion technology which combines the advantages of pressurized combustion and fluidized bed, has been considered as one of the most promising coal utilization technologies. However, although quite a number of experiments as mentioned above has been carried out under pressurized conditions, few of them have been conducted with fluidized bed combustors with continuous fuel feeding. The combustion process of a single fuel particle in a drop tube reactor, a thermogravimetric analyzer or a wire-mesh reactor is significantly different from the fuel combustion process in a fluidized bed combustor with continuous fuel feeding. In addition, the influences of stoichiometric air coefficient, flow regime and interaction between the gas and solids on the fuel combustion process cannot be investigated with the single fuel particle combustion tests as a steady and continuous combustion condition cannot be established with these tests. As Duan et al. [6] pointed out, the only reported work of coal combustion in pressurized fluidized beds was from Lasek [2425], which mainly focused on the pollutant emissions of $\mathrm{NO}_{\mathrm{x}}, \mathrm{SO}_{\mathrm{x}}$ and the transition from air to oxy combustion. Besides, their experiments did not consider the effect of excess air on the pressurized combustion process.

A pressurized fluidized bed combustion system was developed by the authors for a research program focusing on pressurized air and oxy-coal combustion. This paper presents the results of a series of experiments that studied the effects of pressure and stoichiometric air coefficient on the combustion performance of a Chinese lignite coal. 
The temperature profiles and apparent solid holdup along the combustor were thoroughly investigated for different operating conditions. The fly ash and bottom ash were collected and analyzed. A correlation as the functions of pressure and stoichiometric air coefficient was developed to predict the conversion ratio of carbon in coal to $\mathrm{CO}_{2}$.

\section{Experimental}

\subsection{Pressurized fluidized-bed combustion system}

All the experiments were performed in a laboratory-scale test rig schematically shown in Fig. 1. It contains a pressurized fluidized-bed combustor, a coal feed subsystem, a gas supply sub-system, a flue gas cooler, a flue gas analyzer, and a distributed control system which includes the measurement and data acquisition unit. Fig. 2 is the photograph of the rig. The combustor mainly consists of a stainless-steel reactor of 8 $\mathrm{cm}$ i.d. and $180 \mathrm{~cm}$ in height. The maximum operation pressure of the reactor was designed to be $0.6 \mathrm{MPa}$. The combustor can be heated to the set temperature (the maximum value is $800{ }^{\circ} \mathrm{C}$ ) by the electric heaters. The internal temperatures of combustor are measured using k-type thermocouples at 4 points (at 200, 500, 760, and $1400 \mathrm{~mm}$ from the fluidization gas distribution grid, respectively) which are denoted as the temperature of the bed zone (T1), the dense-phase zone (T2), the bottom of dilutephase zone (T3) and the top of dilute-phase zone (T4), correspondingly. Three differential pressure gauges were used to measure the pressure drops along the reactor. The pressure measuring points are at the same height as the temperature measuring 
points, and the pressure drops are denoted as $\Delta \mathrm{P} 1$ (height of $200-500 \mathrm{~mm}$ ), $\Delta \mathrm{P} 2$ (height of 500-760 mm) and $\Delta \mathrm{P} 3$ (height of 760-1400 mm), respectively.

Combustion air was supplied by an air compressor whose highest discharge pressure is $0.6 \mathrm{MPa}$. The pressurized FBC system can maintain a fixed pressure owing to the use of the auto pressure controller. The flue gas was continuously analyzed for $\mathrm{CO}_{2}(0-100$ vol $\%), \mathrm{O}_{2}(0-25 \mathrm{vol} \%), \mathrm{CO}(0-10000 \mathrm{ppm}), \mathrm{NO}(0-5000 \mathrm{ppm}), \mathrm{NO}_{2}(0-1000$ ppm), $\mathrm{N}_{2} \mathrm{O}(0-2000 \mathrm{ppm}), \mathrm{SO}_{2}(0-5000 \mathrm{ppm})$, and $\mathrm{H}_{2} \mathrm{~S}(0-1000 \mathrm{ppm})$ using a flue gas analyzer (MADUR GA-21 plus) during each test. The bottom ash and fly ash were collected and analyzed after the test. The chemical composition of the fly ash is analyzed by an X-ray fluorescence analyzer (ARL9800XP+). 


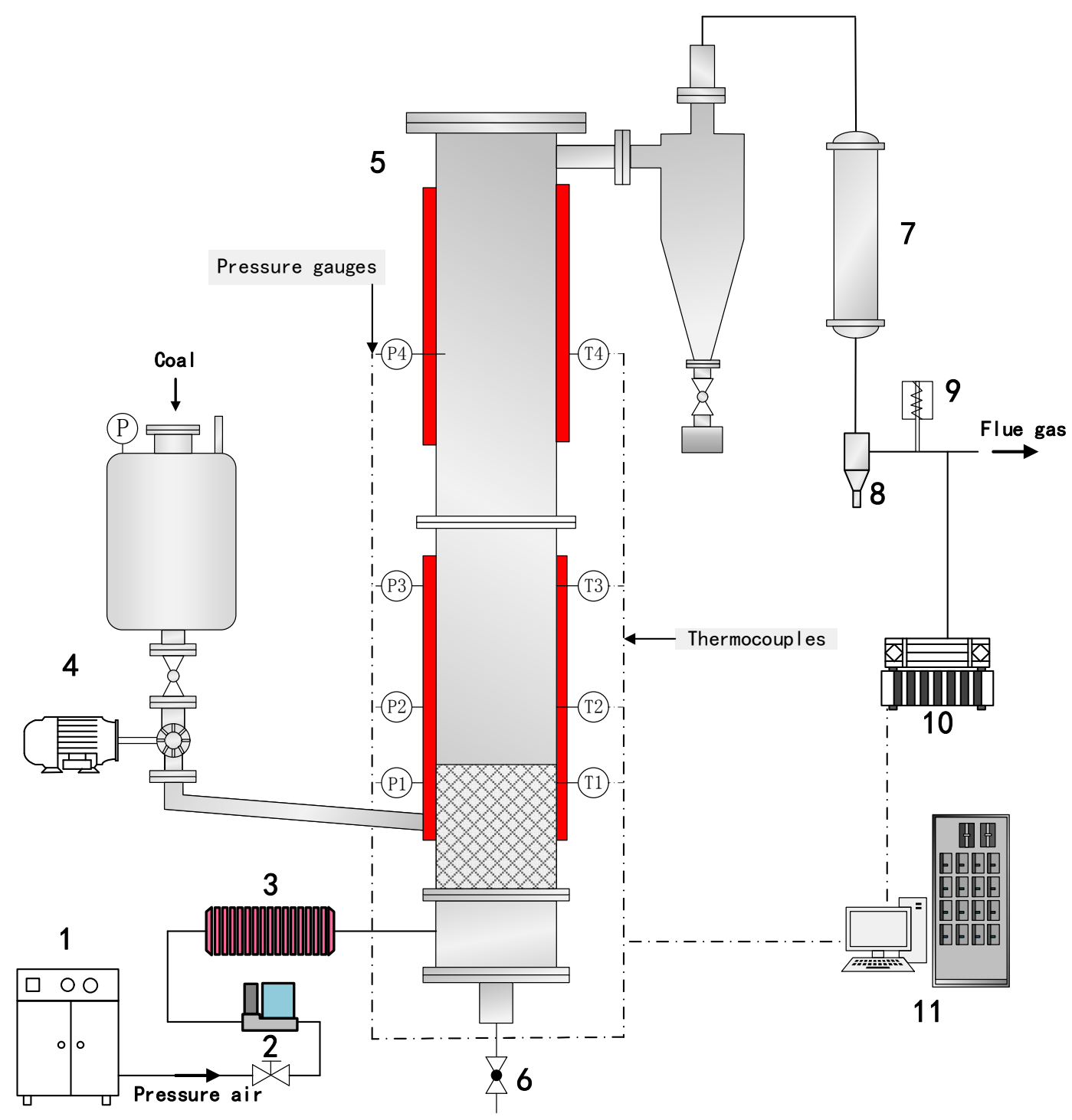

Figure 1. Schematic of the pressurized FBC system. 1. Air compressor 2. Mass flow controller 3. Preheater 4. Coal and sorbent feed sub-system 5. Fluidized bed combustor 6. Ash removal 7. Flue gas cooler 8. Bag filter 9. Auto pressure controller 10. Gas analyzer 11. Distributed control system 


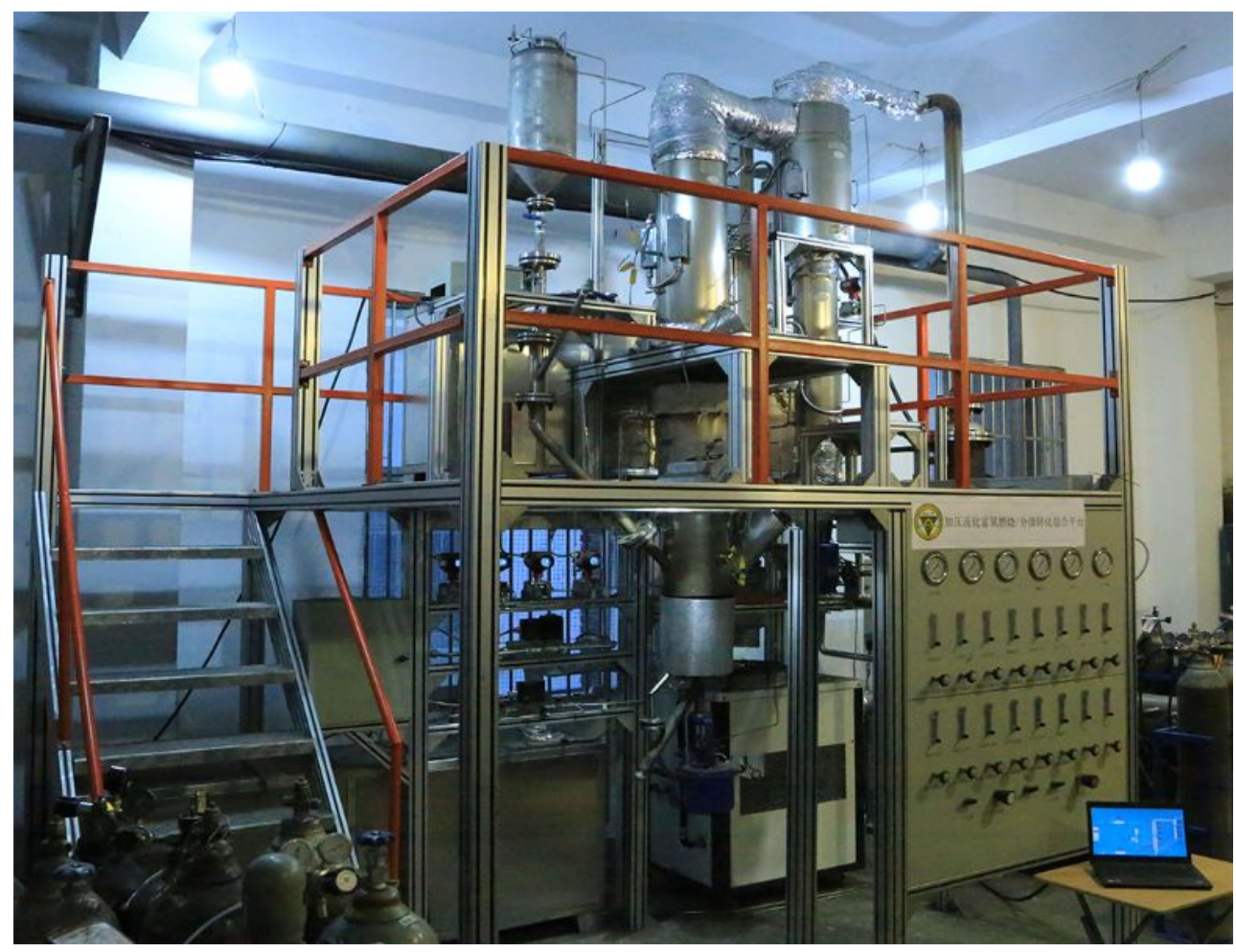

Figure 2. Photograph of the experimental rig

\subsection{Fuel and bed material}

One of typical Chinese coals, Inner Mongolia lignite coal (with a diameter of 0.6$1.4 \mathrm{~mm}$ ) was selected as the fuel and Silica sand (with a diameter of 0.4-1.0 mm) was used as the bed material. The particle size distribution of the silica sand is shown in Fig. 3. The ultimate analysis and proximate analysis of the coal are listed in Table 1. 


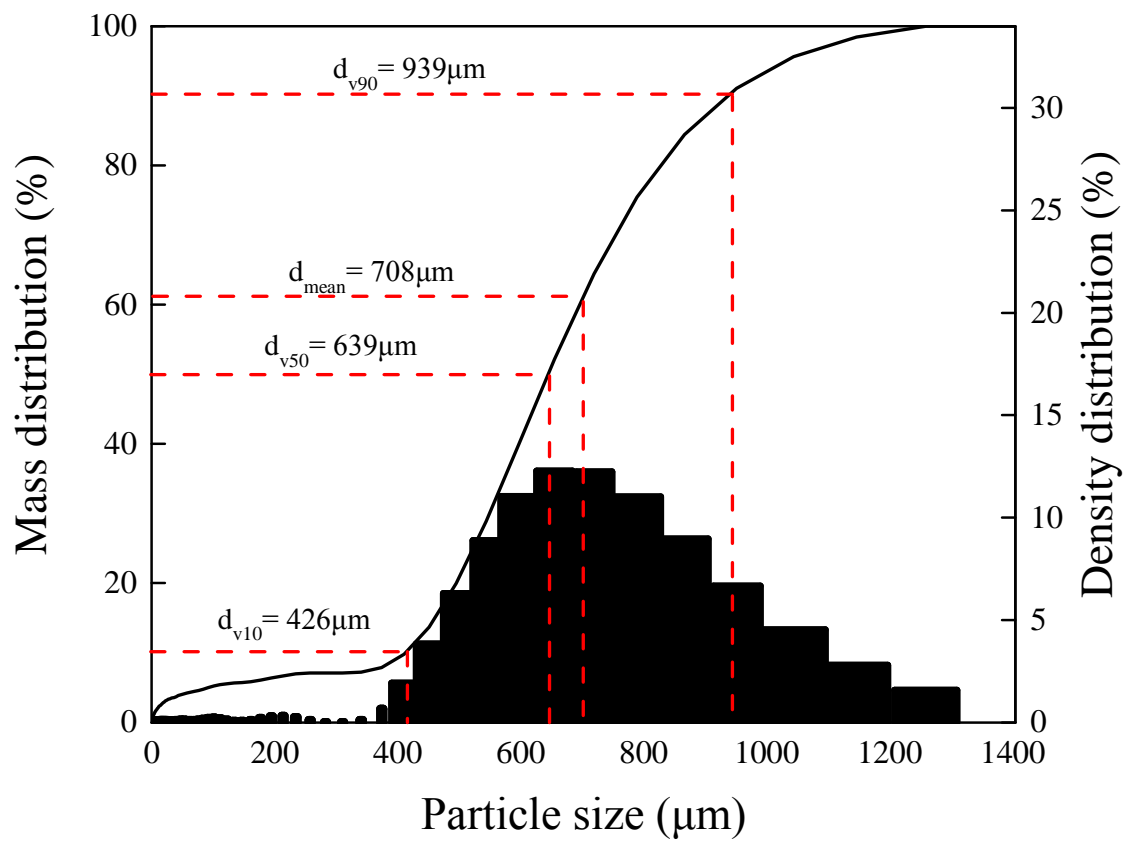

Figure 3. Particle size distribution of silica sand

\subsection{Combustion experiments}

\subsubsection{Experimental procedure}

Before each combustion experiment, the air was preheated to about $600{ }^{\circ} \mathrm{C}$ by the preheater, and the silica sand (with a diameter of $0.4-1.0 \mathrm{~mm}$ and total weight of $2.3 \mathrm{~kg}$ ) was introduced into the fluidized bed combustor and heated to $500{ }^{\circ} \mathrm{C}$ until reaching steady-state conditions (by the electric heater and hot air). Before the coal was fed into the combustor, the gas sample at the outlet of the system was analyzed to make sure that no other fuel existed in the combustor. After this operation, coal was continuously fed into the combustion zone at the predetermined feeding rate and all the electric heaters (except the air preheater) were turned off immediately after the start of coal feeding. The flue gas was depressurized, cooled, sampled and then analyzed by the online gas analyzer. The fly ash was sampled by the bag filter. Fig. 4 shows the 
variations of the measured temperatures with time in a typical experimental process including the preheating stage when the combustor was heated by the electric heaters. It can be seen that during the heating stage, the increase rate of $\mathrm{T} 1$ was much smaller compared with that in the upper region as a result of the silica sand being packed in the bed zone. When the coal was fed into the combustor, all of the measured combustor temperatures sharply increased. Once the stable combustion state was achieved, the operating parameters were adjusted to their desired values. After all the temperatures had stabilized for 30 minutes, which indicated the realization of a steady-state in this work, the experimental data were continuously collected for 60 minutes and then the operating parameters were adjusted to other desired values. After finishing the whole experiment, the coal feeding sub-system was turned off which led to sharp decreases in all temperatures.

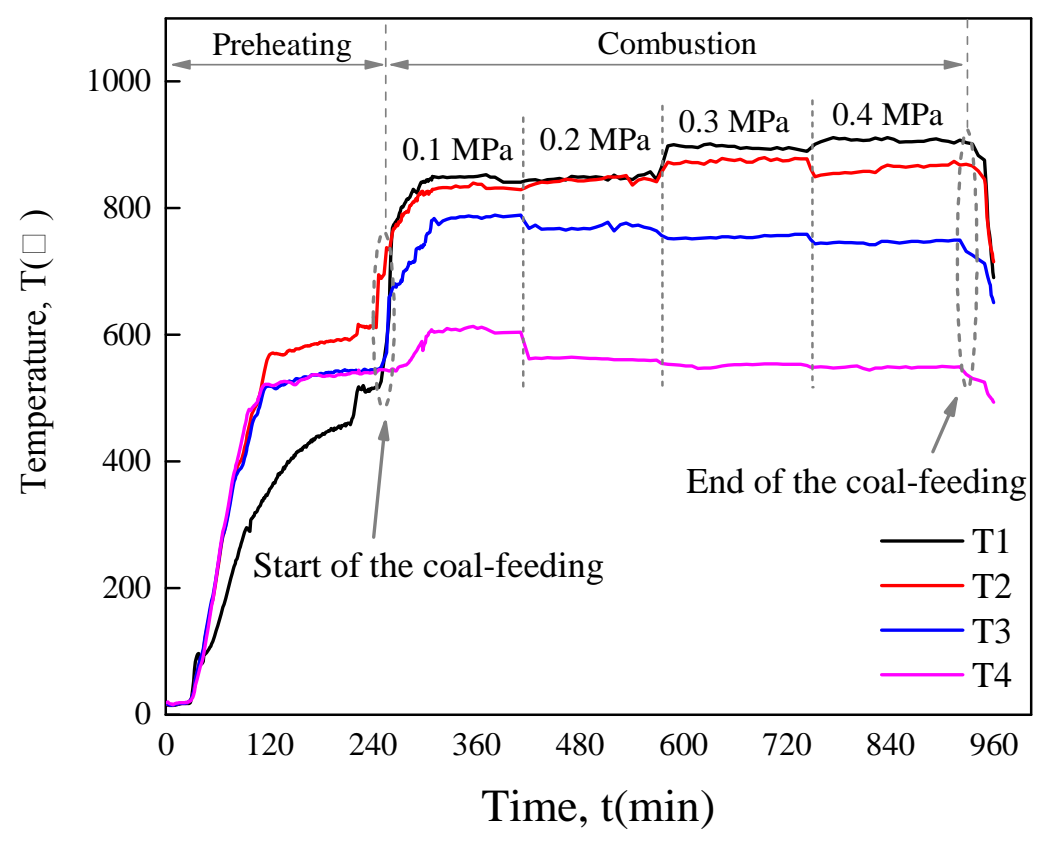

Figure 4. Measured temperatures as a function of time 


\subsubsection{Operating conditions}

Table 2 shows the operating parameters of the experiments reported in this paper. The temperatures of the combustion zone and the pressures inside the system were maintained within the ranges of $850-920{ }^{\circ} \mathrm{C}$ and $0.1-0.4 \mathrm{MPa}$, respectively. The stoichiometric air coefficient $(\beta)$ could be controlled by adjusting the rate of the coal feeding rate and the air input. Because the change of coal feeding rate may result in unwanted excessive temperature fluctuations, the change of stoichiometric air coefficient was realized by changing the inlet air flow rate while keeping the coal feeding rate at a constant level. It is worth mentioning that, for a fluidized bed combustor with the fixed size, the gas velocity decreased with an increase in pressure if the input air flow rate remained constant (because the density of gas increases with pressure). In theory, lower gas velocity is not inherently a result of increased pressure. If the reactor size is smaller, or the air flow rate is higher, the gas velocity can be the same compared with higher combustion pressures. However, the reactor size cannot be changed once it was developed. Besides, to keep the excess air coefficient constant, an increase in air flow rate requires a proportional increase in the coal feeding rate. If the second method is applied, an increase in pressure from 0.1 MPa to 0.4 MPa leads to a quadrupled increase in the coal feeding rate. Furthermore, in order to keep the temperature within a proper range, a cooling system is needed to remove the proper heat accurately under various pressures, which is difficult to realize at bench-scale level. Therefore, a practical design of the experiment is to keep both the coal feeding rate and the air input flow rate the same value under different combustion pressures. In this way, 
the only independent variable is the combustion pressure, and the gas velocity is a dependent variable of the pressure. In this study, the coal feeding rates and air flow rates under different combustion pressures were kept within the same range for most of the experiments (NO.1-21 in Table 2). In order to separate the effect of increased pressure on the combustion efficiency from that of the reduced gas velocity, the other two experiments with the same gas velocity under different combustion pressures were conducted (NO.22-23 in Table 2). The coal feeding rate and air flow rate were increased with the combustion pressure proportionally while the temperature of the combustion zone was kept at the same level, which was realized by the installation of a cooling system. Due to the limited heat exchange capacity of the cooling system, the threefold increase in coal feeding rate under $0.3 \mathrm{MPa}$ cannot be realized.

\section{Results and discussion}

\subsection{Temperature distribution}

\subsubsection{Effect of pressure}

The temperature distribution profiles along the height of combustor under different operating pressures are shown in Fig. 5. It can be seen that the maximum temperatures appear at the bottom zone of the combustor, which indicates that most of the coal particles react and release heat in the dense-phase zone. Above the dense-phase zone, temperatures decrease along the combustor height due to the heat loss. With the same coal feeding rate and excess air coefficient, both $\mathrm{T} 1$ and $\mathrm{T} 2$ increase as combustion pressure increases because of the positive effect of increasing pressure on the coal 
combustion performances. As previous studies [12] with the single coal particle showed that an increase in pressure accelerated the combustion rate, meanwhile the higher oxygen partial pressure on the particle surface increased not only the rates of homogeneous and heterogeneous reactions but also the particle temperature. Besides, the faster combustion rate and higher temperature are beneficial to the burnout of coal particles. As the unburnt carbon decreases (which is shown in section 3.2), more heat is released and the temperature of the dense-bed zone increases.

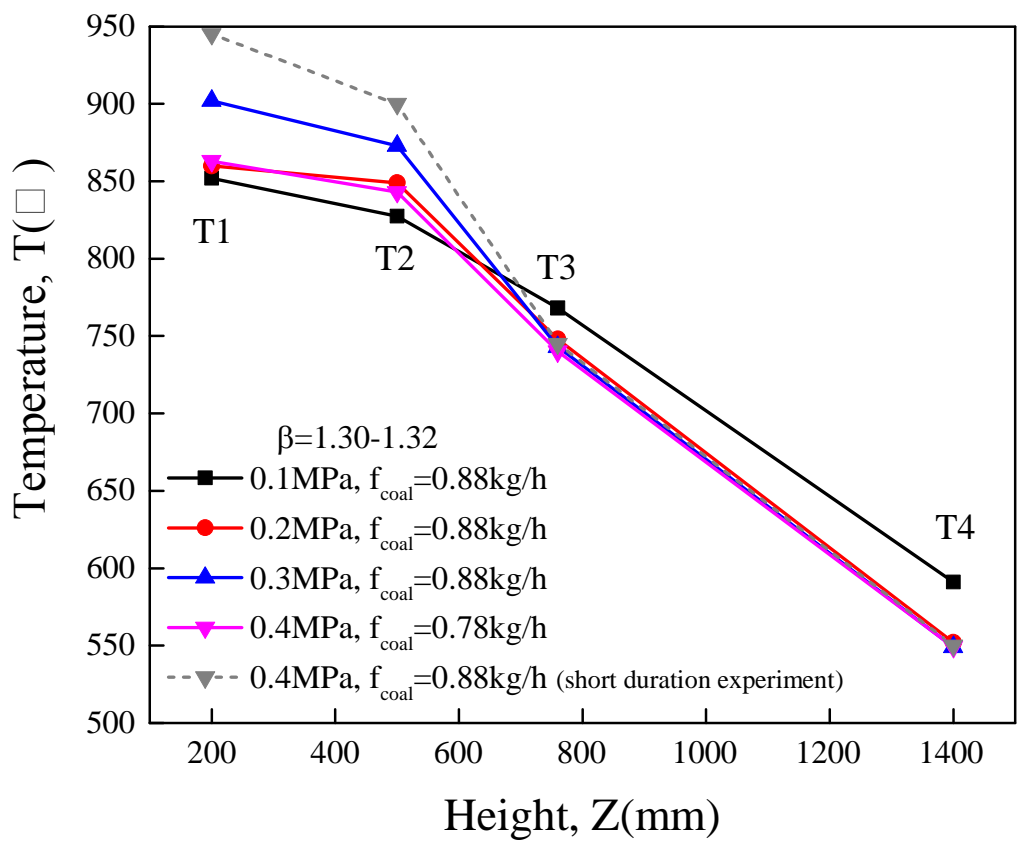

Figure 5. Temperature distributions under different combustion pressures

Fig. 5 shows two different experiments under the pressure of $0.4 \mathrm{MPa}$. The dash line is from the experiment with the coal feeding rate of $0.88 \mathrm{~kg} / \mathrm{h}$ which is the same as that used under the pressures of $0.1-0.3 \mathrm{MPa}$. However, it can be seen that the temperature of the bed zone exceeds $950{ }^{\circ} \mathrm{C}$, which is considered unsafe for long operation of the combustor shell material under such a high pressure. Therefore, the 
coal feeding rate was reduced from $0.88 \mathrm{~kg} / \mathrm{h}$ to $0.78 \mathrm{~kg} / \mathrm{h}$ for safety considerations. The use of the lower coal feeding rate at $0.78 \mathrm{~kg} / \mathrm{h}$ instead of $0.88 \mathrm{~kg} / \mathrm{h}$ under the pressure of $0.4 \mathrm{MPa}$ results in lower $\mathrm{T} 1$ and $\mathrm{T} 2$ values, while they are still comparable to those under the pressure of $0.2 \mathrm{MPa}$. This experimental result also indicates the positive effect of higher pressure on the combustion.

As mentioned in section 2.3.2, the gas velocity in the combustor decreases with an increase in pressure once the air input flow rate is fixed. Therefore, the observed temperature distributions in Fig. 5 are also affected by the differing gas velocities under different pressures. A lower gas velocity leads to a smaller expansion of the solids, which causes a smaller amount of heat transfer from the bottom to the top. Therefore, the temperature differences along the combustor are larger for higher combustion pressures, i.e., the temperature is higher at the bottom.

$$
\varepsilon=\frac{\frac{\Delta P}{\mathrm{~g} \Delta z}-\rho_{g}}{\rho_{\mathrm{p}}-\rho_{\mathrm{g}}}
$$

The average solid holdups in different height zones can be obtained by measuring the corresponding pressure drops. Table 3 shows the average solid holdups predicted by Equation (1) using the measured pressure drops in different zones, where $\varepsilon_{1}, \varepsilon_{2}$, E3 represent the average solid holdups within the bed heights of $200-500 \mathrm{~mm}, 500$ $760 \mathrm{~mm}$ and $760-1400 \mathrm{~mm}$, respectively. It can be seen that with an increase in pressure, $\varepsilon_{1}$ increases while $\varepsilon_{2}$ and $\varepsilon_{3}$ decrease, which indicates that more silica sand particles move from the dilute-phase zone (i.e., 500-1400 mm) to the dense-phase zone (200-500 mm). 
Fig. 6 shows the relation between T3 and $\varepsilon_{2}$ under different combustion pressures. With an increase in pressure, T3 decreases along with $\varepsilon_{2}$. This phenomenon is in agreement with the results of Basu and Nag [19] who found that the heat transfer coefficient increased with the average solid holdup. Besides, the heat transfer coefficient in the pressurized fluidized bed also increases with pressure due to the higher density of gas [21], and hence, T3 decreases under higher pressures. It is also observed that T3 decreases by $20{ }^{\circ} \mathrm{C}$ when the pressure increases from 0.1 to $0.2 \mathrm{MPa}$, while it only decreases by $8{ }^{\circ} \mathrm{C}$ from 0.2 to $0.4 \mathrm{MPa}$. The smaller temperature decrease under higher pressures is caused by the smaller change in solid holdup. As shown in Fig. 6, $\varepsilon_{2}$ sharply reduces from $8.8 \%$ to $5.2 \%$ when the pressure increases from 0.1 to 0.2 $\mathrm{MPa}$, and further increase in pressure from 0.2 to $0.4 \mathrm{MPa}$ just slightly reduces $\varepsilon_{2}$ from $5.2 \%$ to $3.2 \%$. It can be expected that the change in $\varepsilon_{2}$ will become smaller with higher pressure, and eventually its effect on the temperature will be negligible.

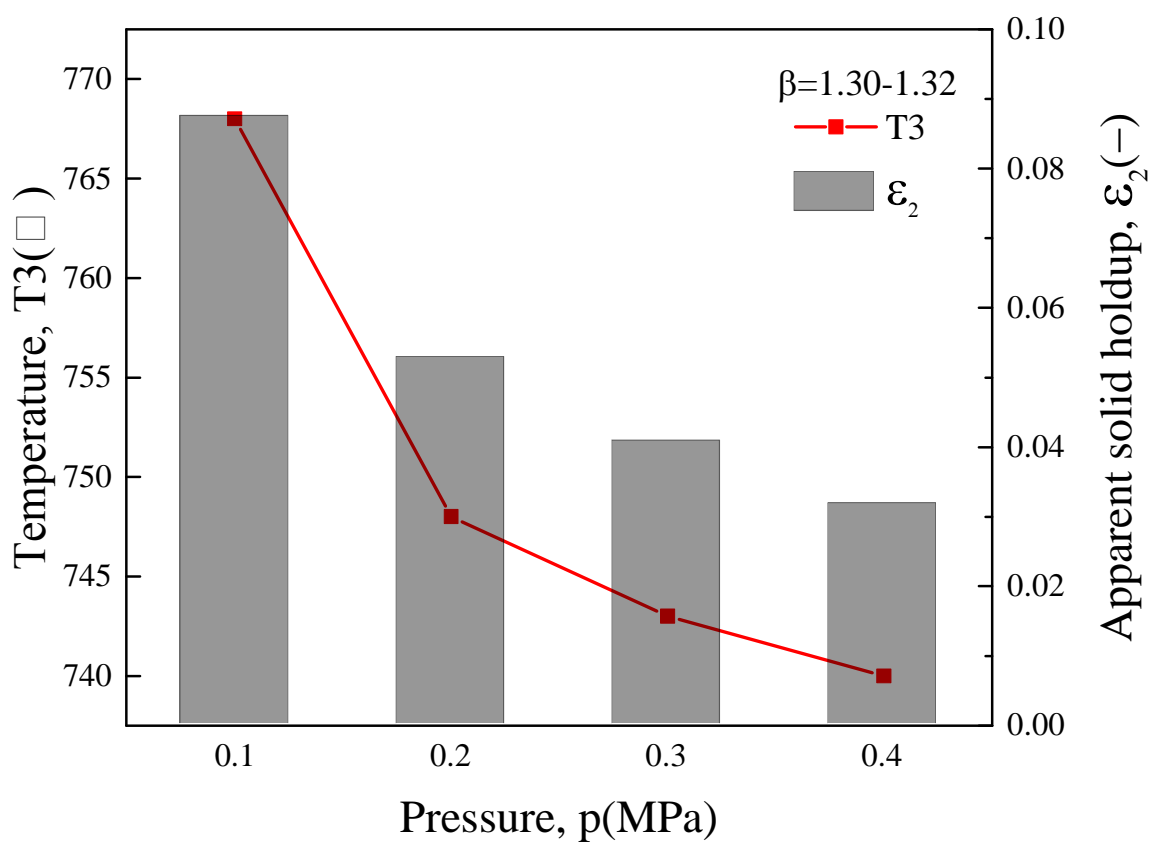


Figure 6. Relation between the temperature and solid holdup under different combustion pressures

The mass of the silica sand particles in different height zones can be calculated through the pressure drop data. Due to the total mass of the silica sand particles in the combustor is fixed $(2.3 \mathrm{~kg})$, the mass of the silica sand particles within the bottom zone (0-200 $\mathrm{mm})$ can be obtained by subtracting the mass of sand particles in other zones (200-1400 mm) from the total mass. The mass fraction distributions of silica sand particles in different height zones are presented in Fig. 7. It is obvious that the expansion of the silica sand bed becomes smaller as the pressure increases. As shown in Fig. 7, when the combustion pressure increases from 0.1 to $0.4 \mathrm{MPa}$, the mass fraction of the sand within the bottom zone $(0-200 \mathrm{~mm})$ increases from $26.4 \%$ to $60.9 \%$ while the mass fractions in other higher zones all decrease.

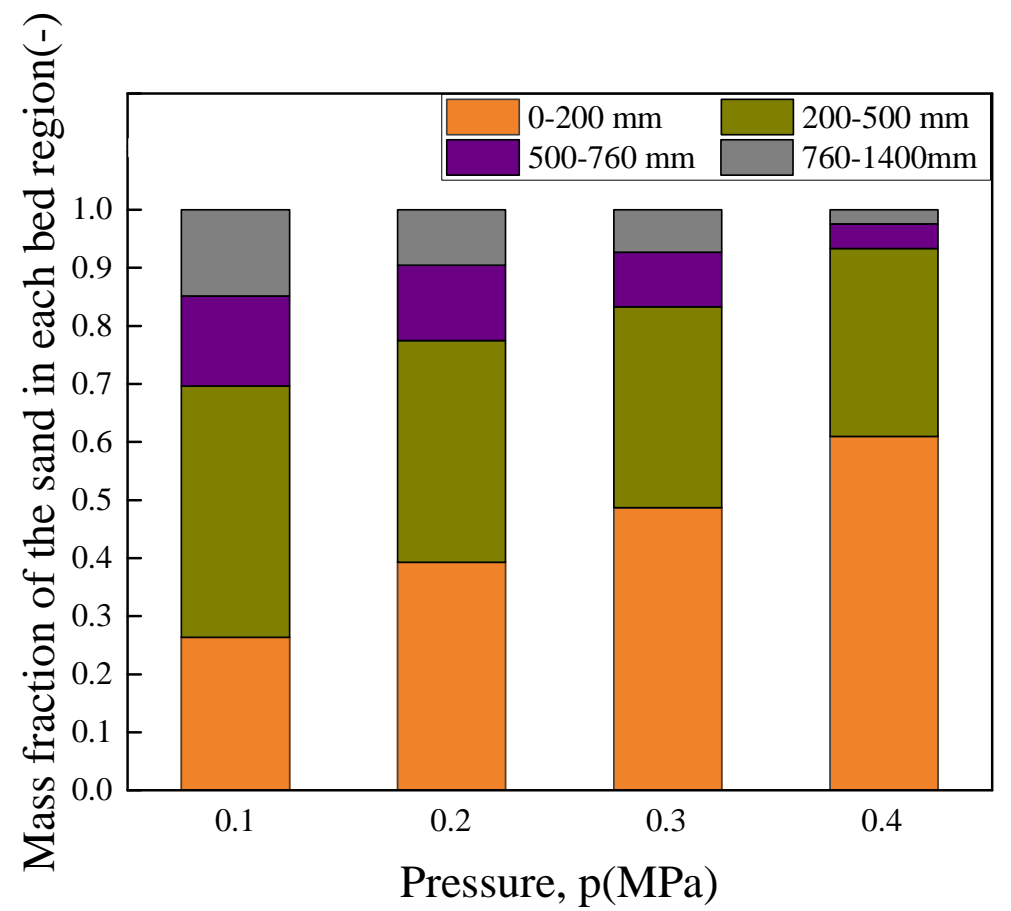

Figure 7. Mass fraction distribution of the silica sand particles under different 
combustion pressures $(\beta=1.30-1.32)$

\subsubsection{Effect of stoichiometric air coefficient}

Table 2 lists the temperature data with different stoichiometric air coefficients $(\beta)$ and Fig. 8 shows the temperature distributions with different $\beta$ under the pressure of 0.2 $\mathrm{MPa}$. Under the same pressure, the temperatures at the higher measuring points (T2, T3 and T4) increase with an increase in $\beta$. On the one hand, the higher stoichiometric air coefficient is beneficial to the burnout of coal particles, and more heat can be released, which increases the temperature. On the other hand, as explained in section $2.3 .2, \beta$ is changed by adjusting the air input. Hence, a higher $\beta$ means not only a more complete combustion but also a higher gas velocity and a better heat transfer. Fig. 9 illustrates the relation between T3 and $\varepsilon_{2}$ with different stoichiometric air coefficients $(\beta)$. With an increase in $\beta$, both the temperatures and solid holdups increase, which is consistent with the explanation in section 3.1.1. Fig. 10 presents the mass fraction distributions of the silica sand particles along the bed with different $\beta$ values. It can be seen that all the sand mass fractions of higher zones $(200-500,500-760,760-1400 \mathrm{~mm})$ increase with the increase in $\beta$ from 1.1 to 1.5 , while the mass fraction of the bottom zone $(0-200 \mathrm{~mm})$ gradually decreases from $56.5 \%$ to $35.3 \%$. The increasing fraction of sand particles in the higher zone indicates a better gas-solid interaction, which also explains why the temperatures at the higher measuring points (i.e., T2, T3 and T4) increase whereas T1 almost remains the same value.

By comparing the influence of $\beta$ on the temperature distribution under different 
combustion pressures, it can be found that $\beta$ has a greater influence on the temperature of $\mathrm{T} 3$ under the pressure of $0.2 \mathrm{MPa}$ and $0.3 \mathrm{MPa}$. As explained in section 3.1.1, the temperature of T3 is mainly determined by the solid holdup ( $\left.\varepsilon_{2}\right)$, however, the positive effects of increasing $\beta$ on $\varepsilon_{2}$ under different pressures are not the same. As shown in Table 3, the increasing range of $\varepsilon_{2}$ is larger at $0.2 \mathrm{MPa}(4.53-9.81 \%)$ and $0.3 \mathrm{MPa}$ (3.02-8.45\%) while it is smaller at $0.1 \mathrm{MPa}(7.85-10.46 \%)$ and $0.4 \mathrm{MPa}(3.16-6.19 \%)$. It is clear that the wider range of $\varepsilon_{2}$, the greater influence of $\beta$ on T3.

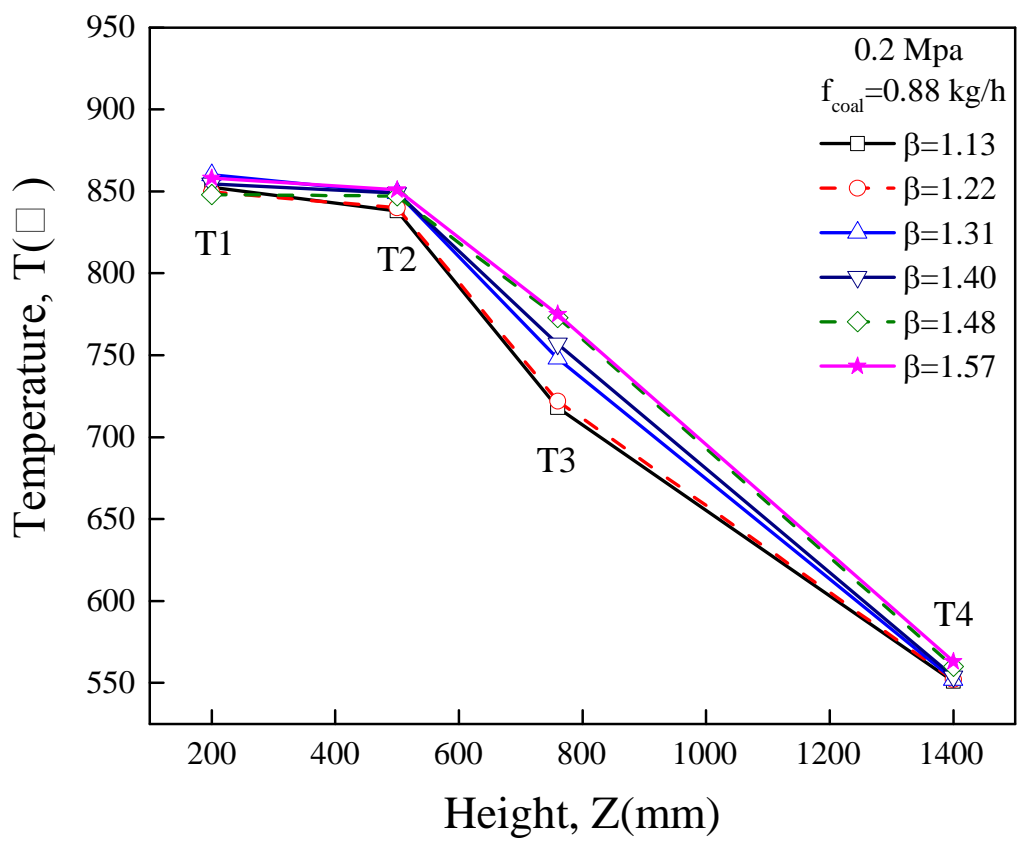

Figure 8. Temperature distributions with different stoichiometric air coefficients 


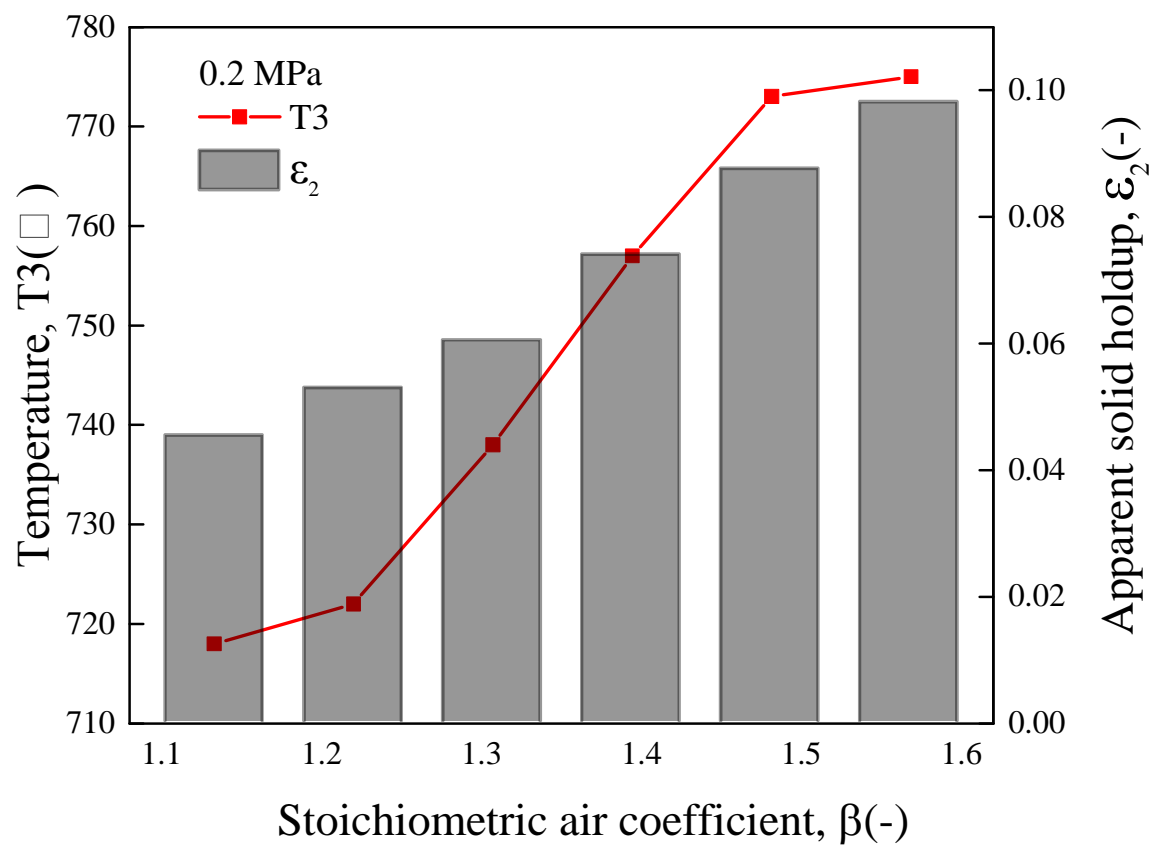

Figure 9. Relation between the temperature and solid holdup with different stoichiometric air coefficients

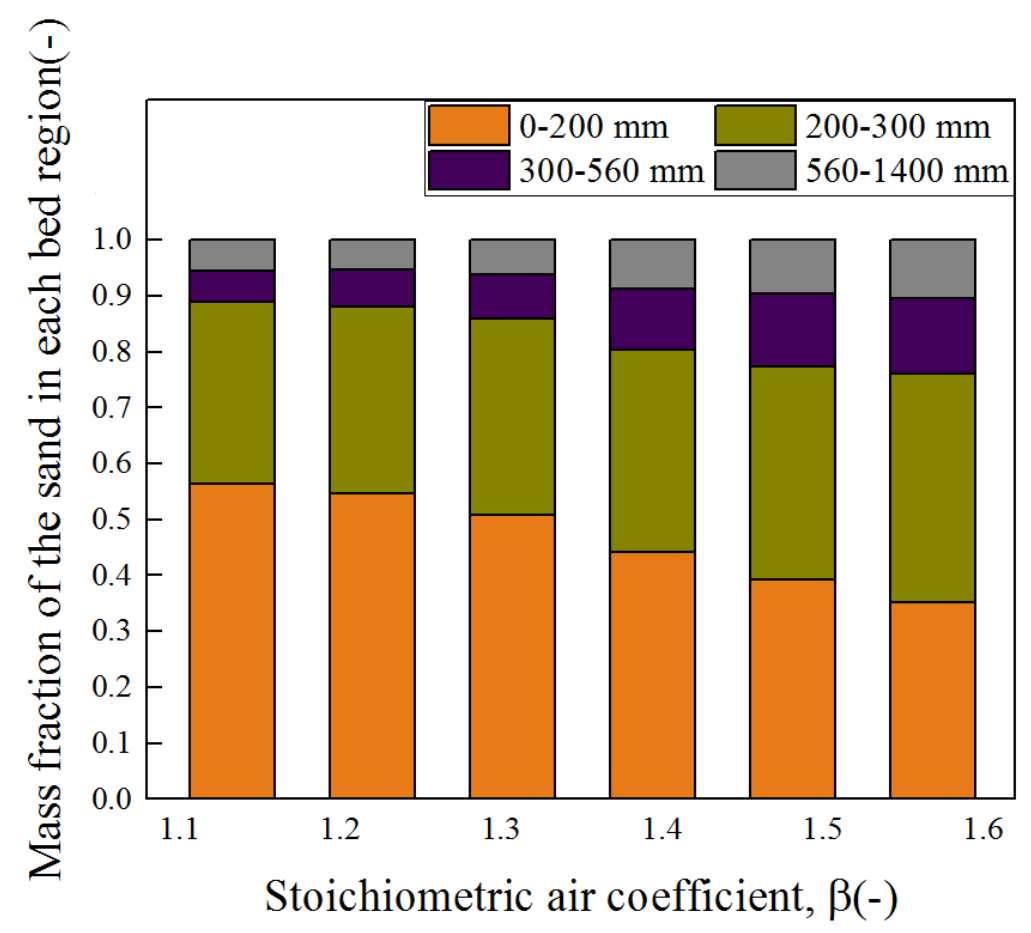

Figure 10. Mass fraction distribution of the silica sand with different stoichiometric air coefficients $(0.2 \mathrm{MPa})$ 


\section{2 Combustion efficiency and conversion ratio of carbon in coal to $\mathrm{CO}_{2}$}

In this section, the combustion efficiency and fuel carbon conversion to $\mathrm{CO}_{2}$ were investigated. The combustion efficiency $(\eta)$ can be calculated by Eqn. (2) [26]:

$$
\eta=1-q_{3}-q_{4}
$$

where $\mathrm{q}_{3}$ and $\mathrm{q}_{4}$ are the efficiency losses associated with the combustible gases and the unburnt carbon, respectively, and can be calculated based on the GB10184-88 and ASME PTC4-1998.

$$
\mathrm{q}_{3}=\frac{Q_{C O}+Q_{H_{2}}+Q_{C H_{4}}}{Q_{\text {net, ar }}}
$$

where $\mathrm{Q}_{\mathrm{CO}}, \mathrm{Q}_{\mathrm{H} 2}$ and $\mathrm{Q}_{\mathrm{CH} 4}$ are the heating values of $\mathrm{CO}, \mathrm{H}_{2}$ and $\mathrm{CH}_{4}$ in the flue gas, respectively. Qnet,ar is the thermal input of the coal.

$$
\begin{gathered}
\mathrm{q}_{4}=\mathrm{q}_{4}^{b a}+\mathrm{q}_{4}^{f a} \\
\mathrm{q}_{4}^{b a}=\frac{Q_{c} * C_{b a} * G_{b a}}{Q_{\text {net, ar }}} \\
\mathrm{q}_{4}^{f a}=\frac{Q_{c} * C_{f a} * G_{f a}}{Q_{\text {net, ar }}}
\end{gathered}
$$

where $\mathrm{q}_{4}^{b a}$ and $\mathrm{q}_{4}^{f a}$ are the efficiency losses associated with the unburnt carbon in bottom ash and fly ash, respectively. $\mathrm{C}_{\mathrm{ba}}$ and $\mathrm{C}_{\mathrm{fa}}$ are the mass ratio of the unburnt carbon in the bottom ash and fly ash, respectively. $\mathrm{G}_{\mathrm{ba}}$ and $\mathrm{G}_{\mathrm{fa}}$ are the mass of bottom ash and fly ash. $\mathrm{Q}_{\mathrm{C}}$ is the heating value of the carbon $\left(\mathrm{Q}_{\mathrm{C}}=32.7 \mathrm{MJ} / \mathrm{kg}\right)$. It is worth mentioning that, in the following paragraph, $\mathrm{q}_{3}$ and $\mathrm{q}_{4}$ represent the experimental results with a fixed coal feeding rate and a fixed air flow rate whereas $\mathrm{q}_{3^{*}}$ and $\mathrm{q}_{4^{*}}$ represent the experiment results with the same gas velocity, i.e. both coal feeding rate and air flow rate were proportionally increased at the higher pressure condition to 
maintain the gas velocity and the residence time the same values as those under the lower pressure condition.

Fig. 11 shows the efficiency losses and combustion efficiencies under different combustion pressures (the solid lines represent the experiments with the same coal feeding rate and air flow rate, whereas the dash lines represent the experiments with the same gas velocity). The two combustion efficiencies achieved with the previous studies [27-28] that had the similar operating parameters to those of this study are shown in Fig. 11 for comparison purpose. It can be noted that, with an increase in the combustion pressure, the efficiency losses associated with the combustible gases $\left(\mathrm{q}_{3}\right.$ and $\left.\mathrm{q}_{3^{*}}\right)$ remain at a small value that can be ignored. The low values of $\mathrm{q}_{3}$ and $\mathrm{q}_{3^{*}}$ are attributed to the low concentrations of $\mathrm{CO}, \mathrm{H}_{2}$ and $\mathrm{CH}_{4}$ in the flue gas. On the other hand, the efficiency losses due to unburnt carbon $\left(\mathrm{q}_{4}\right.$ and $\left.\mathrm{q}_{4^{*}}\right)$ decrease significantly as the combustion pressure increases; specifically, $\mathrm{q}_{4}$ decreases from $12.0 \%$ at 0.1 $\mathrm{MPa}$ to $1.8 \%$ at $0.4 \mathrm{MPa}\left(\mathrm{q}_{4 *}\right.$ decreases from $13.34 \%$ at $0.1 \mathrm{MPa}$ to $10.01 \%$ at 0.2 $\mathrm{MPa}$ ). The data of unburnt carbon in fly ash and bottom ash under different combustion pressures are listed in Table 4. It can be seen that the unburnt carbon in fly ash sharply decreases as the combustion pressure increases, whereas the unburnt carbon in bottom ash remains quite a low value. As shown in Fig. $11, \mathrm{q}_{4}$ reduces by $4.42 \%$ when the pressure increases from 0.1 to $0.2 \mathrm{MPa}$ whereas $\mathrm{q}_{4 *}$ reduces by $3.13 \%$. Both reductions of $\mathrm{q}_{4}$ and $\mathrm{q}_{4 *}$ are a result of better combustion under the higher pressure condition. The significant reduction in $\mathrm{q}_{4 *}$ when the operating pressure is increased from $0.1 \mathrm{MPa}$ to $0.2 \mathrm{MPa}$ is caused by the increased devolatilization and combustion 
rates under the high pressure condition as the residence time and the combustion temperature are almost identical for both pressure conditions. The bigger reduction in $\mathrm{q}_{4}$ when the operating pressure is increased from $0.1 \mathrm{MPa}$ to $0.2 \mathrm{MPa}$, comparing with the reduction in $\mathrm{q}_{4^{*}}$ is mostly attributed to the longer gas residence time with the 0.2 MPa test (NO.9 in Table 2). The results of this study are in agreement with those of Lin et al. [18] who had showed that the reaction rate was higher under the higher pressure conditions when the combustion was under the chemical-kinetic and internal-diffusion control conditions. Therefore, taking both the factors of reaction and flow into consideration, an increase in pressure is helpful to realize highly-efficient combustion of coal. Furthermore, it is observed that the increase rate of combustion efficiency becomes smaller with an increase in pressure. This agrees with the results of Saastamoinen et al. [12] who had pointed out that the effect of pressure increase on the combustion rate was the greatest at the pressure of $0.1 \mathrm{MPa}$ and smaller at higher pressures. 


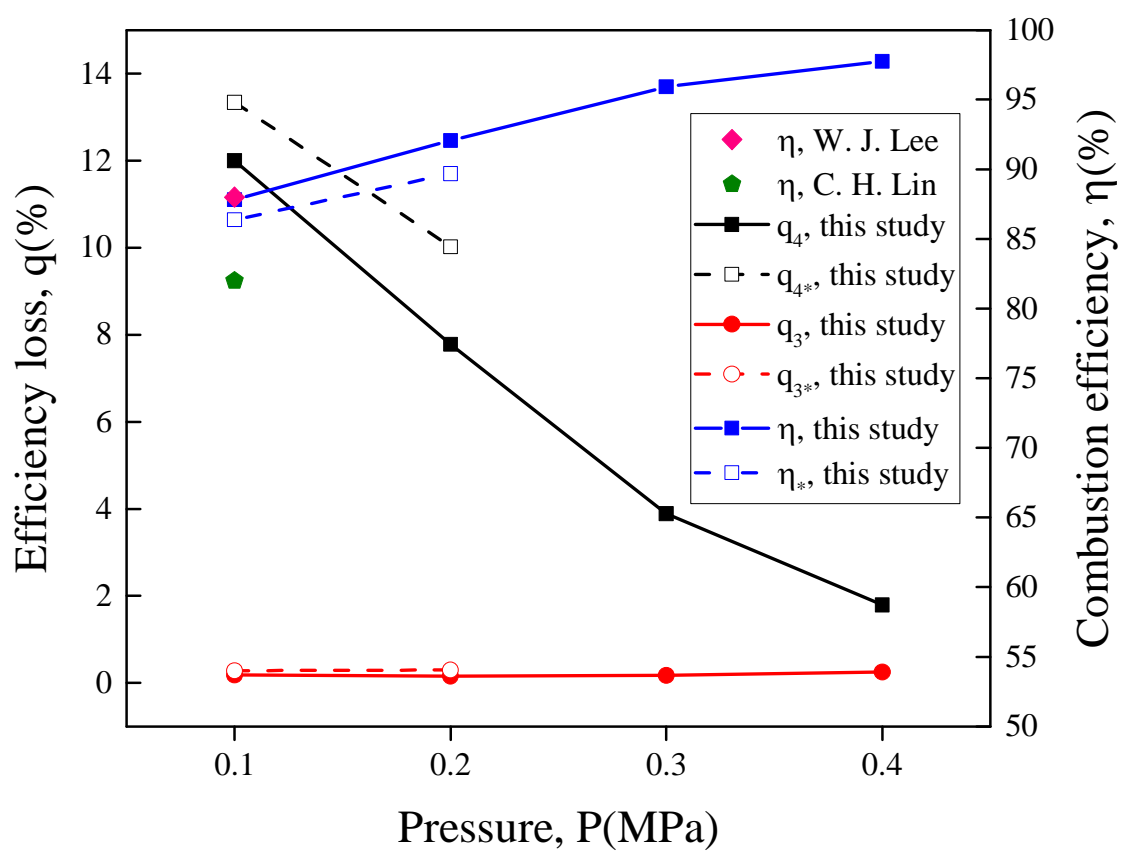

Figure 11. Efficiency losses and combustion efficiency for different combustion pressures (Solid lines represent the experiments with fixed coal feeding rate and air flow rate but a variable gas velocity under different combustion pressures, $\beta=1.48$. Dash lines represent the experiments with fixed gas velocity but an increased coal feeding rate and air flow rate, $\beta=1.1$ )

The stoichiometric air coefficient $(\beta)$ is one of the key operating parameters that influences the combustion efficiency of any combustor. However, according to the knowledge of the authors, no one has systematically investigated the effect of excess air level on coal combustion in pressurized fluidized bed combustors or boilers with continuous coal feeding. In this study, the conversion ratio of carbon in coal to carbon dioxide $(\omega)$ under different operating conditions are investigated. If complete combustion is achieved, all the carbon in coal will be converted to carbon dioxide, i. e., $\omega=100 \%$. Therefore, a higher $\omega$ value means a more complete combustion. 


$$
\omega_{c o_{2}-c}=\frac{\mathbf{M}_{c o_{2}-c}}{\mathrm{f}_{\text {coal }} * \omega_{\text {coal }-c}}
$$

Where $\mathrm{McO}_{2}-\mathrm{c}, \mathrm{f}_{\text {coal }}$ and $\mathrm{w}_{\text {coal-c }}$ are the mass of carbon in $\mathrm{CO}_{2}$, coal feeding rate and mass fraction of carbon in coal, respectively.

Fig. 12 shows the conversion ratios of carbon in coal to $\mathrm{CO}_{2}(\omega)$ with different pressures and stoichiometric air coefficients $(\beta)$. The operating parameters and other measured data are shown in Table 2. It can be seen that, the conversion ratio $(\omega)$ generally increases with an increase in $\beta$ under the same pressure (except No.13 and No.19), which is consistent with the results under atmosphere pressure. Besides, the increase in $\beta$ has a more positive effect on the conversion ratio when the combustion pressure is lower. For example, when $\beta$ increases from 1.22 to $1.48, \omega$ increases by $9.88 \%$ (from $85.06 \%$ to $94.94 \%$ ) under the pressure of $0.1 \mathrm{MPa}$ while it increases by $3.13 \%$ (from $93.37 \%$ to $96.50 \%$ ) under the pressure of $0.3 \mathrm{MPa}$. To better observe the effects of $\beta$ on the conversion ratio of carbon in coal to $\mathrm{CO}_{2}$, an exponential model was used to fit the experimental data and the results are also shown in Fig .12. The exponential model is described in Equation (8), where A, B and C are the three coefficients that associated with pressure. The fitting values of $\mathrm{A}, \mathrm{B}$ and $\mathrm{C}$ are presented in Table 5. 


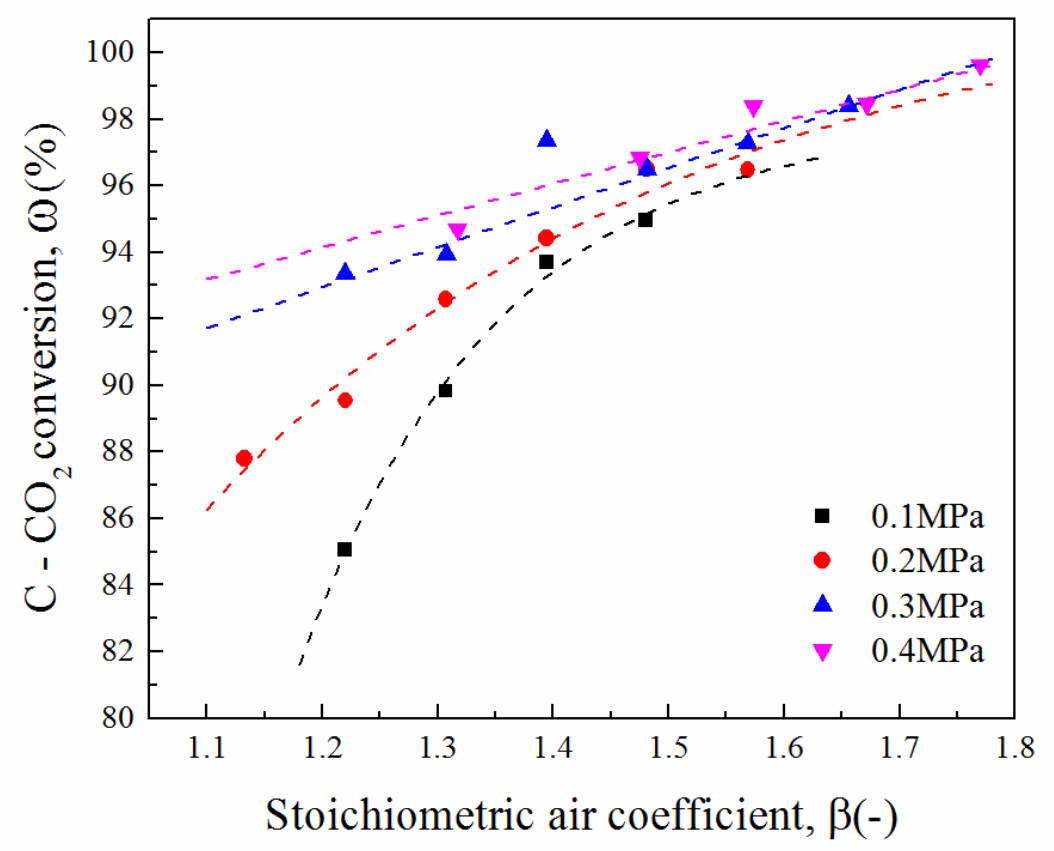

Figure 12. Effect of pressure and stoichiometric air coefficient on the conversion ratio of carbon in coal to $\mathrm{CO}_{2}$

$$
\omega=\mathrm{A}-\mathrm{B} * \mathrm{C}^{\beta}
$$

In order to include the effect of pressure on the conversion ratio, the coefficients (A, B and C) in Equation (8) can be further correlated as functions of pressure (P):

$$
\begin{gathered}
\mathrm{A}=97.91+0.0057 * \mathrm{e}^{33.1 * \mathrm{P}} \\
\mathrm{B}=137.35+2.5191 * \mathrm{e}^{-51.53 * \mathrm{P}} \\
\mathrm{C}=-0.0076+0.00116 * \mathrm{e}^{22.22 * \mathrm{P}}
\end{gathered}
$$

When the pressure increases from 0.1 to $0.3 \mathrm{MPa}, \mathrm{B}$ sharply decreases, which indicates a smaller impact of $\beta$ on $\omega$. Besides, the value of A significantly increases due to a more complete combustion under higher pressure condition and hence a higher value of $\omega$. It is worth mentioning that, the experimental results obtained under the pressure of $0.4 \mathrm{MPa}$ are similar to those obtained under the pressure of $0.3 \mathrm{MPa}$, which 
can be seen from the two almost overlapping lines in Fig. 12. As explained earlier, the positive effect of increasing pressure becomes smaller when the pressure reaches a relatively high level. However, the similar data of conversion ratio in Fig. 12 between those of $0.3 \mathrm{MPa}$ and $0.4 \mathrm{MPa}$ are also attributed to the adjustment of the coal feeding rate. In section 3.1.1, it has been stated that the coal feeding rate is decreased from 0.88 to $0.78 \mathrm{~kg} / \mathrm{h}$ under $0.4 \mathrm{MPa}$ for safety reasons. As a result, $\mathrm{T} 1$ and $\mathrm{T} 2$ under the pressure of $0.4 \mathrm{MPa}$ are lower than those under the pressure of $0.3 \mathrm{MPa}$, which makes $\omega$ lower than it should be. It can be expected that the value of $\omega$ under the pressure of $0.4 \mathrm{MPa}$ will exceed that of $0.3 \mathrm{MPa}$ if the coal feeding rate is kept the same as that under 0.3 $\mathrm{MPa}$ (i.e., $0.88 \mathrm{~kg} / \mathrm{h}$ ). From the fitting curves in Fig .12, it is clear that the increase in combustion pressure results in a higher conversion ratio when $\beta$ is smaller than 1.4. For an actual fluidized bed boiler, although increasing $\beta$ to 1.4 or even higher may increase the combustion efficiency, it is not recommended due to the extra heat loss associated with the large excess air in the flue gas and the higher power consumption of the air blower. In addition, an increase in $\beta$ may also lead to other negative effects, e.g., a higher emission of nitric oxide [29]. Therefore, pressurized fluidized bed boilers are also expected to be operated within the typical range of $\beta$ adopted by other solid combustion processes (1.1-1.3). The results show in Fig. 12 indicate the positive effect of high pressure on the conversion ratio of coal carbon to carbon dioxide is very significant within the typical range of excess air level.

\subsection{Chemical composition of fly ash and bottom ash}


The chemical compositions of fly ash and bottom ash (excluding the unburnt carbon) under different combustion pressures are shown in Fig. 13. As it can be observed from Fig. 13, the ash under the pressures of 0.1 to $0.4 \mathrm{MPa}$ has similar chemical composition. For the fly ash, the dominant species in the fly ash are $\mathrm{SiO}_{2}$, $\mathrm{Al}_{2} \mathrm{O}_{3}$ and $\mathrm{Fe}_{2} \mathrm{O}_{3}$, and the sum of these three species is over $80 \%$. The other species such as $\mathrm{SO}_{3}, \mathrm{CaO}, \mathrm{TiO}_{2}, \mathrm{P}_{2} \mathrm{O}_{5}, \mathrm{MgO}$ and $\mathrm{K}_{2} \mathrm{O}$ are only present in small fractions. Besides, with an increase in combustion pressure, the mass fractions of $\mathrm{SO}_{3}$ and $\mathrm{CaO}$ in fly ash decrease, which indicates that high pressure weakens the self-desulfurization efficiency of the fly ash. Compared with fly ash, the mass fractions of $\mathrm{Fe}_{2} \mathrm{O}_{3}, \mathrm{SO}_{3}$ and $\mathrm{CaO}$ in the bottom ash are significantly smaller. This phenomenon was also observed by other researchers [30-31] under atmospheric pressure, which showed that the release of compounds of $\mathrm{Ca}, \mathrm{Mg}, \mathrm{Fe}$ and $\mathrm{S}$ from coal and their interaction with bed materials caused bed agglomeration. For a fluidized bed combustor which is operated at a steady state, the majority of these elements are retained in the fly ash instead of the bottom ash. 

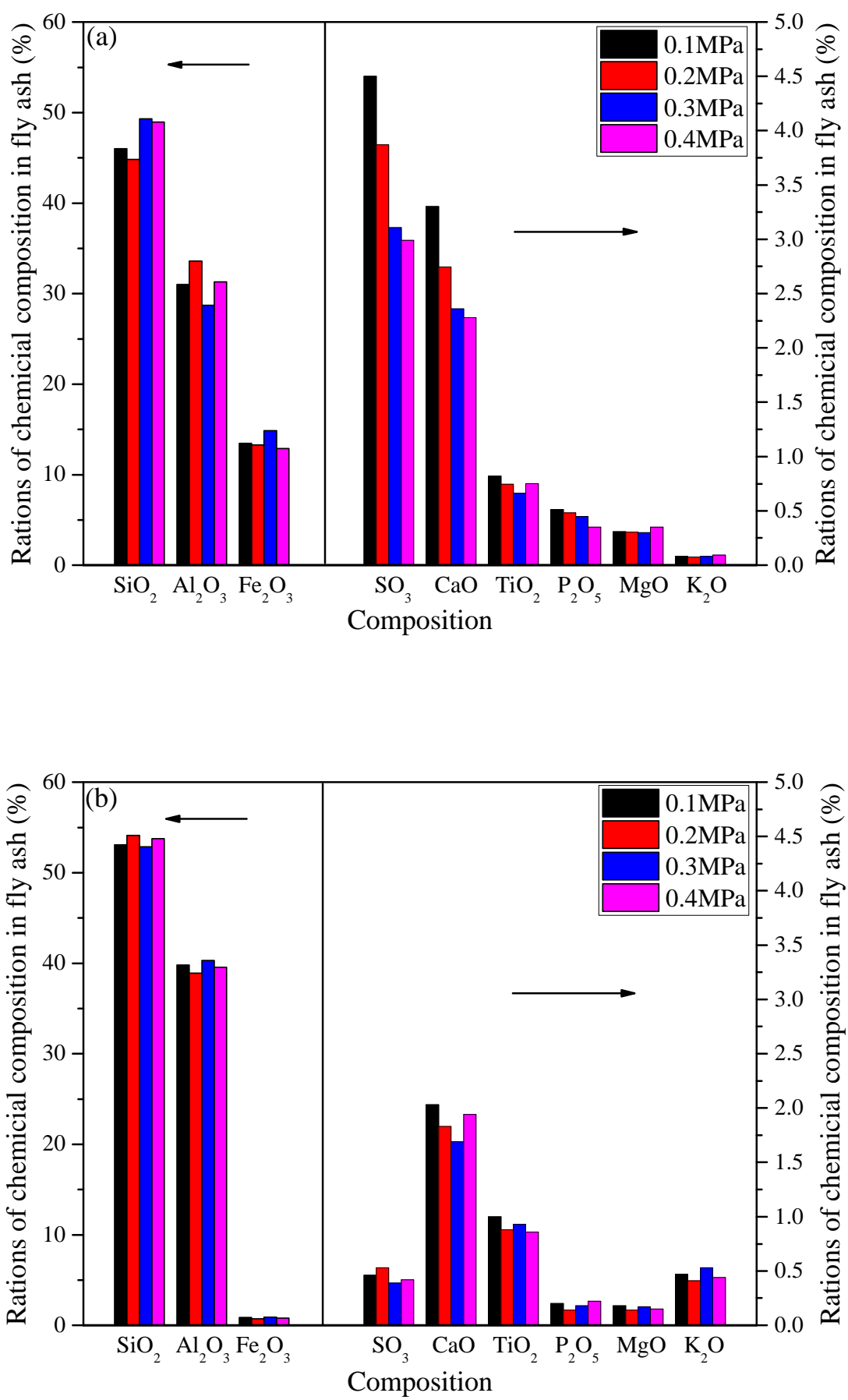

Figure 13. Chemical composition (wt\%) of ash under different combustion pressures

(a) fly ash, (b) bottom ash 


\section{Conclusions}

With the developed pressurized fluidized bed combustion system, a series of coal combustion experiments were carried out under the pressures of 0.1 to $0.4 \mathrm{MPa}$. The effects of combustion pressure and stoichiometric air coefficient on the fluidized bed combustion performances were investigated. The apparent solid holdups and temperature distributions along the combustor were thoroughly investigated for different operating conditions. The following conclusions can be drawn from the experimental results:

(1) The combustion efficiency significantly increases with an increase in the combustion pressure due to a lower efficiency loss resulted from unburnt carbon.

(2) A correlation as the functions of combustion pressure and stoichiometric air coefficient is proposed and developed for the prediction of the conversion ratio of carbon in coal to $\mathrm{CO}_{2}$. The conversion ratio increases with an increase in pressure and excess air. The positive effect of increasing the excess air on the conversion ratio is more prominent under lower operating pressures.

(3) Due to the higher combustion efficiency and the smaller expansion of the solids, the temperature of the bed zone increases with an increase in combustion pressure.

(4) The combustion pressure has no significant impact on the chemical composition of ash as both the fly ash and bottom ash have similar compositions under different combustion pressures.

The results of this study have shown significant advantages of pressurized-air combustion against atmospheric-air combustion in terms of combustion efficiency and 
carbon conversion ratio. However, when pressurized combustion is combined with oxycoal combustion, it will have another major advantage in carbon capture and storage, i.e., improvement in net plant efficiency, and hence our future work will focus on the experimental investigation of pressurized fluidized bed oxy-coal combustion using the same pressurized fluidized bed combustion test facility.

\section{Nomenclature}

$\begin{array}{ll}\text { C } & \text { Mass fraction } \\ d_{p} & \text { Diameter of the particle } \\ g & \text { Gravitational acceleration } \\ \mathrm{p} & \text { Pressure } \\ \mathrm{Q} & \text { Heating value } \\ \mathrm{q} & \text { Heat loss } \\ \mathrm{T} & \text { Temperature } \\ \mathrm{t} & \text { Time } \\ \mathrm{Z} & \text { Height }\end{array}$

\section{Greek Symbols}

$\rho_{\mathrm{p}}$

$\rho_{\mathrm{g}}$

$\alpha$
Density of the particle

Density of the gas

Excess air coefficient

Stoichiometric air coefficient 
$\varepsilon$

$\mu$

$\omega$
Solid holdup

Viscosity

Conversion ratio of carbon in coal to $\mathrm{CO}_{2}$

\section{Acknowledgement}

This work was supported by National Key R\&D Program of China (2016YFB0600802) and Key R\&D Program of Jiangsu Province (BE2017195).

\section{References}

[1] Scheffknecht G, Al-Makhadmeh L, Schnell U, et al. Oxy-fuel coal combustion A review of the current state-of-the-art. Inter J Greenh Gas Con, 5S (2011), pp. S16S35.

[2] Carrasco-Maldonado F, Sporl R, Fleiger K, et al. Oxy-fuel combustion technology for cement production - State of the art research and technology development. Inter $\mathbf{J}$ Greenh Gas Con, 45 (2016), pp. 189-199.

[3] Mathekga H I, Oboirien B O, and North B C, A review of oxy-fuel combustion in fluidized bed reactors. Int J Energy Res, 40 (2016), pp. 878-902.

[4] Sher F, Pans M A, Sun C, et al. Oxy-fuel combustion study of biomass fuels in a 20 kWth fluidized bed combustor. Fuel, 215 (2018), pp. 778 - 786.

[5] Chen L, Yong S Z, Ghoniem A F. Oxy-fuel combustion of pulverized coal: Characterization, fundamentals, stabilization and CFD modeling. Prog Energ Combust, 38 (2012), pp. 156-214.

[6] Duan Y, Duan L, Anthony E J, et al. Nitrogen and sulfur conversion during 
pressurized pyrolysis under $\mathrm{CO}_{2}$ atmosphere in fluidized bed. Fuel, 189 (2017), pp. 98106.

[7] Hong J, Field R, Gazzino M, et al. Operating pressure dependence of the pressurized oxy-fuel combustion power cycle. Energy, 35 (12) (2010), pp. 5391-5399.

[8] Zebian H, Gazzino M, Mitsos A. Multi-variable optimization of pressurized oxycoal combustion. Energy, 38 (1) 2012, pp. 37-57.

[9] Gopan A, Kumfer B M, Axelbaum R L. Effect of operating pressure and fuel moisture on net plant efficiency of a staged, pressurized oxy-combustion power plant. Inter J Greenh Gas Con, 39 (2015), pp. 390-396.

[10] Hagi H, Nemer M, Moullec Y L, et al. Towards second generation oxy-pulverized coal power plants: energy penalty reduction potential of pressurized oxy-combustion systems. Energy Procedia, 63 (2014), pp. 431-439.

[11] Xia F, Yang Z, Adeosun A, et al. Pressurized oxy-combustion with low flue gas recycle: computational fluid dynamic simulations of radiant boilers. Fuel, 181 (2016), pp. 1170-1178.

[12] Saastamoinen J J, Aho M J, Hamalainen J P, et al. Pressurized pulverized fuel combustion in different concentrations of oxygen and carbon dioxide. Energ Fuel, 10(1996), pp. 121-133.

[13] Lu Y. Laboratory studies on devolatilization and char oxidation under PFBC conditions. 1. Volatile release and char reactivity. Energ Fuel, 10 (2) (1996), pp. 348356.

[14] Macneil S, Basu P. Effect of pressure on char combustion in a pressurized 
circulating fluidized bed boiler. Fuel, 77 (4) (1998), pp. 269-275.

[15] Monson C R, Germane G J, Blackham A U, et al. Char oxidation at elevated pressures. Combust Flame, 100 (1995), pp. 669-683.

[16] Lester T W, Seeker W R, Merklin J F. The influence of oxygen and total pressure on the surface oxidation rate of bituminous coal. Symposium on Combustion, 18 (1) (1981), pp. 1257-1265.

[17] Bateman K J, Germane G J, Smoot L D, et al. Effect of pressure on oxidation rate of millimetre-sized char particles. Fuel, 74 (10) (1995), pp. 1466-1474.

[18] Lin S Y, Suzuki Y, Hatano H, et al. Pressure effect on char combustion in different rate-control zones: initial rate expression. Chem Eng Sci, 55 (1) (2000), pp. 43-50.

[19] Basu P, Nag P K. Heat transfer to walls of a circulating fluidized-bed furnace. Chem Eng Sci, 51 (1) (1996), pp. 1-26.

[20] Kalita P, Saha U K, Mahanta P. Parametric study on the hydrodynamics and heat transfer along the riser of a pressurized circulating fluidized bed unit. Exp Therm Fluid Sci, 44 (2013), pp. 620-630.

[21] Fermoso J, Gil M V, Borrego A G, et al. Effect of the pressure and temperature of devolatilization on the morphology and steam gasification reactivity of Coal Chars. Energ Fuel, 24 (10) (2010), pp. 5586-5595.

[22] Lei $\mathrm{M}$, Huang $\mathrm{X}$, Wang $\mathrm{C}$, et al. Investigation on $\mathrm{SO}$, NO and NO2 release characteristics of Datong bituminous coal during pressurized oxy-fuel combustion. J Therm Anal Calorim, 126 (3) (2016), pp. 1067-1075.

[23] Zeng D, Fletcher T H. Effects of pressure on coal pyrolysis and char morphology. 
Energ Fuel, 19 (5) (2005), pp. 1828-1838.

[24] Lasek J A, Glod K, Janusz M, et al. Pressurized Oxy-fuel Combustion: A Study of Selected Parameters. Energ Fuel, 26 (11) (2012), pp. 6492-6500.

[25] Lasek J A, Janusz M, Zuwała J, et al. Oxy-fuel combustion of selected solid fuels under atmospheric and elevated pressures. Energy, 62 (2013), pp. 105-112.

[26] Man C B, Zhu J G, Ouyang Z Q, et al. Experimental study on combustion characteristics of pulverized coal preheated in a circulating fluidized bed. Fuel Process Technol, 172 (2018), pp. 72-78.

[27] Lin C H, Teng J T, Chyang C S. Evaluation of the combustion efficiency and emission of pollutants by coal particles in a vortexing fluidized bed. Combust Flame, 110 (1997), pp. 163-172.

[28] Lee W J, Cho Y J, Kim J R, et al. Coal combustion characteristics in a fluidized bed combustor with a draft tube. Korean J Chem Eng, 9 (4) (1992), pp. 206-211.

[29] Duan L, Zhao C, Zhou W, et al. Effects of operation parameters on NO emission in an oxy-fired CFB combustor. Fuel Process Technol, 92 (3) (2011), pp. 379-384.

[30] Roy B, Bhattacharya S. Ash characteristics during oxy-fuel fluidized bed combustion of a Victorian brown coal. Powder Technol, 288 (2016), pp. 1-5.

[31] Wu H, Bryant G, Wall T. The effect of pressure on ash formation pulverized coal combustion. Energ Fuel, 14 (2000), pp. 745-750. 
Table 1. Ultimate analysis and proximate analysis of coal sample

\begin{tabular}{|c|c|c|c|c|c|c|c|c|c|}
\hline \multirow[t]{2}{*}{ Sample } & \multicolumn{5}{|c|}{ Ultimate analysis (\%) } & \multicolumn{4}{|c|}{ Proximate analysis (\%) } \\
\hline & $\mathbf{C a d}_{\text {ad }}$ & $\mathbf{H}_{\text {ad }}$ & $\mathbf{O}_{\text {ad }}$ & $\mathbf{N}_{\mathbf{a d}}$ & $\mathbf{S}_{\mathbf{a d}}$ & $\mathbf{F C}_{\mathbf{a d}}$ & $\mathbf{V}_{\mathbf{a d}}$ & $\mathbf{A}_{\text {ad }}$ & $\mathbf{M}_{\mathbf{a d}}$ \\
\hline lignite & 65.83 & 3.01 & 5.68 & 1.07 & 2.01 & 61.8 & 15.8 & 19.1 & 3.3 \\
\hline
\end{tabular}

*ad-air dried 
Table 2. Experimental results: average values of the main process parameters

\begin{tabular}{|c|c|c|c|c|c|c|c|c|c|c|c|}
\hline No & $\begin{array}{c}\text { Pressure } \\
\text { (MPa) }\end{array}$ & $\begin{array}{c}\text { Air } \\
(\mathrm{kg} / \mathrm{h})\end{array}$ & $\begin{array}{c}\text { Fuel input } \\
(\mathrm{kg} / \mathrm{h})\end{array}$ & $\beta$ & $\begin{array}{c}\text { T1 } \\
\left({ }^{\circ} \mathrm{C}\right)\end{array}$ & $\begin{array}{c}\text { T2 } \\
\left({ }^{\circ} \mathrm{C}\right)\end{array}$ & $\begin{array}{c}\text { T3 } \\
\left({ }^{\circ} \mathrm{C}\right)\end{array}$ & $\begin{array}{c}\text { T4 } \\
\left({ }^{\circ} \mathrm{C}\right)\end{array}$ & $\begin{array}{c}\text { O2 out } \\
(\text { Vol \%) }\end{array}$ & $\begin{array}{c}\mathrm{CO}_{2} \\
(\mathrm{Vol} \%)\end{array}$ & $\begin{array}{c}\mathrm{CO} \\
(\mathrm{ppm})\end{array}$ \\
\hline 1 & 0.1 & 9.03 & 0.88 & 1.22 & 850 & 822 & 758 & 587 & 6.19 & 13.3 & 288 \\
\hline 2 & 0.1 & 9.68 & 0.88 & 1.31 & 852 & 827 & 768 & 591 & 6.32 & 13.1 & 332 \\
\hline 3 & 0.1 & 10.32 & 0.88 & 1.39 & 848 & 830 & 780 & 603 & 6.97 & 12.8 & 267 \\
\hline 4 & 0.1 & 10.97 & 0.88 & 1.48 & 846 & 832 & 782 & 608 & 7.80 & 12.2 & 284 \\
\hline 5 & 0.2 & 8.39 & 0.88 & 1.13 & 852 & 838 & 718 & 551 & 4.68 & 14.8 & 274 \\
\hline 6 & 0.2 & 9.03 & 0.88 & 1.22 & 850 & 840 & 722 & 552 & 5.30 & 14.0 & 268 \\
\hline 7 & 0.2 & 9.68 & 0.88 & 1.31 & 860 & 849 & 748 & 552 & 6.10 & 13.5 & 221 \\
\hline 8 & 0.2 & 10.32 & 0.88 & 1.39 & 855 & 849 & 757 & 554 & 6.72 & 12.9 & 272 \\
\hline 9 & 0.2 & 10.97 & 0.88 & 1.48 & 848 & 847 & 773 & 560 & 7.60 & 12.4 & 281 \\
\hline 10 & 0.2 & 11.61 & 0.88 & 1.57 & 858 & 851 & 775 & 563 & 8.38 & 11.7 & 268 \\
\hline 11 & 0.3 & 9.03 & 0.88 & 1.22 & 904 & 866 & 737 & 550 & 4.87 & 14.6 & 274 \\
\hline 12 & 0.3 & 9.68 & 0.88 & 1.31 & 902 & 873 & 743 & 549 & 5.86 & 13.7 & 238 \\
\hline 13 & 0.3 & 10.32 & 0.88 & 1.39 & 906 & 887 & 754 & 555 & 6.35 & 13.3 & 275 \\
\hline 14 & 0.3 & 10.97 & 0.88 & 1.48 & 900 & 888 & 760 & 555 & 7.35 & 12.4 & 376 \\
\hline 15 & 0.3 & 11.61 & 0.88 & 1.57 & 887 & 886 & 812 & 566 & 8.18 & 11.8 & 192 \\
\hline 16 & 0.3 & 12.23 & 0.88 & 1.66 & 883 & 882 & 827 & 579 & 8.92 & 11.3 & 239 \\
\hline 17 & 0.4 & 8.64 & 0.78 & 1.31 & 863 & 843 & 740 & 549 & 6.13 & 13.7 & 662 \\
\hline 18 & 0.4 & 9.68 & 0.78 & 1.48 & 906 & 857 & 745 & 545 & 7.44 & 12.5 & 419 \\
\hline 19 & 0.4 & 10.32 & 0.78 & 1.57 & 907 & 869 & 747 & $\mathbf{5 5 0}$ & 7.93 & 11.9 & 234 \\
\hline 20 & 0.4 & 10.97 & 0.78 & 1.67 & 898 & 872 & 751 & 551 & 8.73 & 11.2 & 230 \\
\hline 21 & 0.4 & 11.61 & 0.78 & 1.77 & 894 & 878 & 758 & 553 & 9.32 & 10.7 & 214 \\
\hline $22^{*}$ & 0.1 & 9.16 & 0.99 & 1.10 & 850 & 830 & 770 & 565 & 4.10 & 15.7 & 783 \\
\hline $23^{*}$ & 0.2 & 18.33 & 2.00 & 1.09 & 855 & 850 & 806 & 630 & 3.32 & 16.6 & 814 \\
\hline
\end{tabular}

*after the cooling system was installed (the higher fuel input of NO. 22 than that of NO.1 is caused by the stronger heat exchange with the installed cooling water tubes) 
Table 3. The predicted average solid holdups for different zones

\begin{tabular}{|c|c|c|c|c|c|}
\hline No & $\begin{array}{c}\text { Pressure } \\
\text { (MPa) }\end{array}$ & $\beta$ & $\begin{array}{c}\mathcal{E}_{1} \\
(\%)\end{array}$ & $\begin{array}{c}\mathcal{E}_{2} \\
(\%)\end{array}$ & $\begin{array}{l}\varepsilon_{3} \\
(\%)\end{array}$ \\
\hline 1 & 0.1 & 1.22 & 21.98 & 7.85 & 2.88 \\
\hline 2 & 0.1 & 1.31 & 23.03 & 8.76 & 2.94 \\
\hline 3 & 0.1 & 1.39 & 24.57 & 9.86 & 2.74 \\
\hline 4 & 0.1 & 1.48 & 25.38 & 10.46 & 4.09 \\
\hline 5 & 0.2 & 1.13 & 18.32 & 3.77 & 1.53 \\
\hline 6 & 0.2 & 1.22 & 18.97 & 4.53 & 1.43 \\
\hline 7 & 0.2 & 1.31 & 19.89 & 5.28 & 1.72 \\
\hline 8 & 0.2 & 1.39 & 21.20 & 7.40 & 2.39 \\
\hline 9 & 0.2 & 1.48 & 22.37 & 8.76 & 2.64 \\
\hline 10 & 0.2 & 1.57 & 23.29 & 9.05 & 2.88 \\
\hline 11 & 0.3 & 1.22 & 18.32 & 3.02 & 1.53 \\
\hline 12 & 0.3 & 1.31 & 18.97 & 4.08 & 1.41 \\
\hline 13 & 0.3 & 1.39 & 19.63 & 5.13 & 1.97 \\
\hline 14 & 0.3 & 1.48 & 20.28 & 6.34 & 2.02 \\
\hline 15 & 0.3 & 1.57 & 21.59 & 7.40 & 2.70 \\
\hline 16 & 0.3 & 1.66 & 22.24 & 8.45 & 3.00 \\
\hline 17 & 0.4 & 1.31 & 17.66 & 3.17 & 0.55 \\
\hline 18 & 0.4 & 1.48 & 18.97 & 2.87 & 0.67 \\
\hline 19 & 0.4 & 1.57 & 19.89 & 3.93 & 0.19 \\
\hline 20 & 0.4 & 1.67 & 20.01 & 5.43 & 0.15 \\
\hline 21 & 0.4 & 1.77 & 21.06 & 6.19 & 0.18 \\
\hline
\end{tabular}


Table 4. The mass ratio of unburnt carbon in fly ash and bottom ash

\begin{tabular}{cccc}
\hline $\begin{array}{c}\text { Pressure } \\
(\mathrm{MPa})\end{array}$ & $\boldsymbol{\beta}$ & $\begin{array}{c}\text { Unburnt C in fly ash } \\
(\%)\end{array}$ & $\begin{array}{c}\text { Unburnt C in bottom ash } \\
(\%)\end{array}$ \\
\hline 0.1 & 1.31 & 27.97 & 1.02 \\
0.2 & 1.31 & 20.10 & 1.31 \\
0.3 & 1.31 & 11.21 & 0.88 \\
0.4 & 1.32 & 5.57 & 1.09 \\
\hline 0.1 & 1.10 & 30.15 & 1.42 \\
0.2 & 1.09 & 24.48 & 0.97 \\
\hline
\end{tabular}


Table 5. The fitting values of three coefficients

\begin{tabular}{cccc}
\hline Pressure (MPa) & A & B & C \\
\hline 0.1 & 98.067 & 14696.9 & 0.00316 \\
0.2 & 102.190 & 221.5 & 0.09135 \\
0.3 & 215.240 & 137.8 & 0.90511 \\
0.4 & 218.012 & 136.0 & 0.92500 \\
\hline
\end{tabular}

